\title{
LAS BASES TEÓRICAS DE LAS NARRACIONES AUTOBIOGRÁFICAS DE LOS DOCENTES
}

\section{Theoretical foundations of teachers' autobiographies narratives}

\section{Fernando GIL CANTERO}

Universidad Complutense. Facultad de Educación. Departamento de Teoría e Historia de la Educación. C/. Rector Villanova, s/n. 28040. Madrid.

Fecha de aceptación definitiva: marzo de 2000.

BIBLID [(1130-3743) 11, 1999, 159-181]

RESUMEN

En este artículo me centro en un apartado específico de la narrativa que tiene particular relevancia para los educadores de todos los niveles educativos: la narrativa personal de los profesores. Se subrayan así algunas características claves de la narrativa: A) proporcionar significado a la experiencia temporal y a las acciones personales, B) sintetizar las acciones y los sucesos cotidianos en unidades de episodios, C) estructurar los sucesos del pasado y planear los sucesos del futuro. Voy a usar los términos narrativa del profesor (o relatos de los profesores) para referirme a los sucesos o acontecimientos de las experiencias en el aula, compartidas bien a través del lenguaje oral o escrito, y usadas para ayudar a los profesores a pensar más profundamente sobre el significado de la enseñanza, el aprendizaje y ayudar a crecer personalmente y a cambiar, tanto profesional como personalmente. Este artículo discute las consecuencias positivas y negativas de los diferentes modos de desarrollar la identidad de los profesores desde una perspectiva filosófica.

SUMMARY

In this paper I focus on a subset of narrative that has particular relevance for educators at all levels: the teacher personal narrative. It highlights some key features 
of the narrative: A) ascribing meaning to temporal experience and personal actions, B) synthesizing everyday actions and events into episodic units, C) structuring past events and planning future events. I am using the terms teacher narrative (or teacher's story) to refer to acttual accounts of classroom experience, shared via written or oral language, and used to help teachers think more deeply about the meaning of teaching and learning and to grow and change, both personally and profesionally. This paper discuss the positive and negative consequences of the different ways to develop the teachers' identity from a philosophical perspective.

El objetivo de este artículo estriba en analizar críticamente algunos de los supuestos filosóficos de las teorías educativas que pretenden mejorar la formación inicial y continua de los docentes a través de la escritura autobiográfica. Desde hace algún tiempo se está desarrollando, con el apoyo de un gran empuje bibliográfico, algunos procedimientos de formación (historias de vida, autobiografías guiadas, anecdotarios, diarios, evocación de recuerdos, entrevistas biográficas, etc.) de los docentes basados en la propuesta de que éstos adopten la perspectiva de rememorar sus experiencias de clase y de su vida particular ${ }^{1}$.

Estos supuestos se van a obtener, por un lado, del análisis de los términos habitualmente implicados en los estudios semánticos y filosóficos de las narraciones autobiográficas, lo que nos llevará a proponer una vinculación nueva, escasamente cultivada en nuestro contexto académico, entre la Pedagogía y la Narratología. Por otra parte, dedicaré un segundo apartado a desarrollar las bases filosóficas de la formación de la identidad, lo que se ha dado en llamar en esta línea de investigación "referencia de los textos autobiográficos" y que se plantea en un debate internacional muy extendido entre varias corrientes de pensamiento. Esta discusión, como veremos, tiene su proyección pedagógica, entre otras cuestiones, en el modo en que decidamos armonizar los planteamientos normativos de la Pedagogía, con las experiencias únicas e individuales de las narraciones autobiográficas de los docentes. A lo largo de estos análisis, en algún momento, mostraremos, a título de ejemplo, las peculiares relaciones que, en ocasiones, mantienen las narraciones autobiográficas con ciertas mentalidades dominantes y fenómenos sociales como la atomización e individualización de la propia vida, el sentido huidizo e inaprensible de la existencia y lo que algún destacado escritor ha denominado "la dictadura de lo secundario" en la más reciente literatura autobiográfica.

Ahora bien, no pretendo quedarme en un análisis filosófico. La Pedagogía tiene que salir de su ámbito específico para valorar los más diversos intereses culturales, único modo de plantear una educación a la altura de nuestro tiempo y preparada para el futuro. Pero la Pedagogía, si queremos que sea algo más que un divertimiento teórico, tiene también que saber volver, iniciar un viaje de vuelta, para ayudar a mejorar la práctica y los juicios de valor de los docentes. En este sen-

1. El texto de BOLÍVAR, DOMINGO y FERNÁNDEZ (1998) constituye la mejore recapitulación, en castellano, de temas y tendencias sobre esta línea de investigación. 
tido, el último apartado tratará de ofrecer algunas aportaciones que nos ayuden a mejorar la interpretación formativa de las prácticas autobiográficas realizadas por profesores. Este objetivo forma parte de la pretensión más amplia de elaborar una propuesta pedagógica sobre las posibilidades y límites de los enfoques narrativos en la educación.

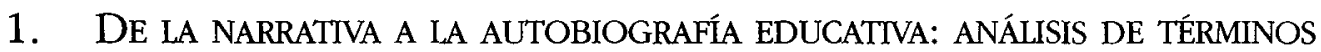

En 1969 Tzvetan Todorov acuñó el término “Narratología" para "designar el estudio científico de los actos de comunicación que tengan como rasgo o propiedad común provocar el efecto de una perspectiva transitiva del mundo entre el agente de dicho acto y el texto hablado o escrito" (TODOROV, 1969, citado en W. GODZICH, 1989 , p. IX). Para David Coste "el objeto de estudio de la Narratología es la producción, transmisión e intercambio de información sobre los cambios y las simulaciones de los cambios en cualquier acto de comunicación" (COSTE, 1989, p. 5).

La narratología es un ámbito de estudio teórico que adopta la narrativa como modalidad de representación y de comunicación. Estamos, pues, refiriéndonos $a$ la relación que media entre quienes establecen un acto de comunicación (hablan, cuentan, imaginan, escriben o leen) y el objeto textual de dicha comunicación (relato, anécdota, diario, novela, cuento, sueño, fábula, etc.). De este modo, la Narratología estudia los posibles cambios que se suceden en los agentes que hablan, imaginan, escriben o leen, y los cambios que se perciben en el "texto" al ser hablados de nuevo, imaginados otra vez, reescritos o vueltos a leer por cada uno de nosotros ${ }^{2}$. Aunque hay aficionados para casi todo, podríamos estar de acuerdo, en principio, que leer las tediosas hojas del BOE o las "Páginas Amarillas" difícilmente se constituiría en una situación narratológica.

Cuando leemos o contamos un cuento a un niño estamos generando una situación formativa en la que, junto a otros beneficios, está aprendiendo a responder afectivamente a situaciones imaginadas o reales y, sobre todo, a comprender el relato mediante diversos recursos que proyectará en su vida. En la mayoría de los casos, no adquiere ningún conocimiento científico de la realidad pero sí un saber comprensivo de las situaciones humanas, de sus sentimientos y de sus intenciones. Para Stibbs, los niños llegan a comprender cómo viven cuando toman conciencia de lo que leen y de lo que les contamos (cfr. STIBBS, 1991, p. 134). De igual modo, los profesores Jover y Reyero indican que “(...) no generamos las representaciones de nosotros y de los otros a partir precisamente del mundo de la ciencia, sino a través de influencias mucho más sutiles: de lo que oímos y de lo que vemos acerca

2. La Narratología estudiará también, aunque de modo indirecto, los cambios que ella misma puede provocar en la percepción de la realidad y de la ficción. En este sentido, cada vez es más evidente cómo el conocimiento de determinados hechos históricos está influenciado, sobre todo para quienes no los han vivido, por sus diversas representaciones literarias y cinematográficas. 
de nosotros mismos y los demás" (JOVER y REYERO, 1999, p. 4; vid. LARROSA, 1996). El cuento, la fábula, el relato...son así, desde la narratología, un texto que genera comunicación mientras representa una parte de la realidad. Al contar un cuento desvelamos ante el niño un acontecimiento, una situación, una trama, que el niño vive como una propuesta para situarse, como una expectativa de sucesos $y$, en su caso, de llamada a su propio cambio ${ }^{3}$.

Todos tenemos la experiencia de lo que sucede, por ejemplo, cuando volvemos a un libro que ya habíamos leído, sobre todo, si es un texto del que guardamos buenos recuerdos. En general y si la memoria no nos falla, al tomar de nuevo el texto podemos sentirnos distintos a como éramos la primera vez que lo leímos. También, a veces, aunque sea ocioso decirlo, el libro cuyas palabras, frases, párrafos y, en su caso, capítulos siguen siendo los mismos y con idéntico orden, sin embargo, para nosotros, como escritores o lectores, pueden adquirir nuevos significados. Así, puede ocurrir que donde nada nos interpeló, encontremos hoy algo especialmente significativo o, por el contrario, que lo que en su día nos pareció iluminador, ahora no lo sea.

En este ejemplo observamos cómo el texto que permanece constante en su estructura, a lo largo del tiempo, sirve de referencia para reconocer los cambios en uno mismo, sus cambios en las preferencias literarias o en las ideas o en sus estados de ánimo y, entonces, el texto en su segunda y, en su caso, sucesivas lecturas ya no es, en realidad, el mismo. Otra vez, como veíamos antes con los cuentos que se relatan a los niños, al releer o visionar de nuevo lo que ya conocemos, recreamos una situación, un acontecimiento, en el que están presentes o se evocan con mayor o menor facilidad, lo que fuimos en contraste con lo que somos, lo que deseábamos y lo que ahora deseamos, lo que pensábamos y sentíamos con lo que en este momento pensamos y sentimos. Al enfrentarnos de nuevo con un texto que, en su momento, nos fue significativo, generamos un tiempo de inquietud en el que reconocemos nuestra trayectoria clara o confusa, determinante o dubitativa. Pues bien, ¿quépasaría si el texto que escribimos y releemos fuese el de nuestra propia trayectoria como educadores? ¿Nos ayudaria a descubrir posibles cambios en nosotros mismos? ¿Cambiaría nuestra comprensión de la educación?

El objeto material de la Narratología es la narrativa. Siguiendo con nuestros análisis conceptuales, nos encontramos con que, según el Diccionario de la Aca-

3. Como señala Ricoeur, la imaginación es una categoría de la acción porque "la lectura (...) implica también un momento de envio: es entonces cuando la lectura se convierte en una provocación para ser y obrar de otro modo: sigue siendo cierto que el envío se transforma en acción sólo gracias a una decisión que hace decir a cada uno jaquí estoy!" (RICOEUR, 1996, Tomo III, p. 1001, cursiva del autor). Es curioso cómo el mercado ha desvirtuado esta idea con los diseños personalizados de cuentos -interesantes desde otros puntos de vista- en los que se proporciona previamente las características del niño para elaborar una trama en la que él o ella, con sus nombres y apellidos, son los protagonistas. Digo desvirtuado, en este caso, porque se trata, en la propuesta de Ricoeur, de la aparición del autoconocimiento por comparación, emulación o rechazo hacia otros personajes reales o ficticios. 
demia, la "Narrativa" es la habilidad para narrar, lo perteneciente o relativo a la narración y, por última acepción, un género literario en prosa, que abarca la novela y el cuento. Si miramos un poco más arriba veremos que la "Narración" es la acción y el efecto de narrar, también es la exposición de una serie de hechos reales o imaginarios que se producen a lo largo del tiempo.

En este caso, no hay una coincidencia plena entre los significados que nuestro diccionario da a estos términos y el modo en que habitualmente se utilizan en la bibliografía especializada. Y, sin embargo, la diferencia juega, esta vez, a nuestro favor. En efecto, la Narratología no se limita a los géneros literarios en prosa, sea la novela o el cuento, sino que incluye en principio el estudio de cualquier conjunto de acciones reales o ficticias que dé lugar a un acto de comunicación narrativo, esto es, que induzca una perspectiva sobre el mundo. Cuando nos referimos a la narrativa no tenemos, pues, que pensar sólo en las narraciones literarias, sino también en cualquier modalidad de expresión que produzca alguna forma de representación o de comunicación.

Para algunos autores como Coste la narrativa es, básicamente, un adjetivo, no un sustantivo: es una propiedad que distingue a diferentes actos de comunicación. Por eso, es habitual considerar, en los estudios narratológicos, que la propiedad común a todas las posibles expresiones de narraciones, literarias o no, lo define de forma más precisa el término "narratividad. Se ha definido la narratividad como "(...) la capacidad que posee el texto narrativo de facultar al receptor el acceso a acciones de dimensión humana, de matriz temporal y englobadas en universos internamente coherentes" (REIS y LOPES, 1996, p. 172). Si antes señalábamos que la narratología se ocupaba de estudiar la relación que media entre un agente y su texto, ahora ya podemos añadir que esa relación, la narratividad, es un "fenómeno de sucesión de estados y de transformaciones, inscrito en el discurso y responsable de la producción de sentido" (GROUPE D'ENTREVERNES, 1979, p. 14).

Esta característica es especialmente interesante para entender y aplaudir el empuje de las propuestas narrativas en educación. En efecto, superadas ya las estrechas miras nomológicas que excluían al educador como agente principal de las propuestas educativas, hoy ya hay una mayor unanimidad en reconocer que la tarea de los educadores es una labor basada en la adopción sopesada y prudente de juicios o perspectivas. Ayudar a la educadores a formarse requiere colaborar con ellos a que adopten juicios de valor sobre lo que han hecho o están a punto de proponer.

De este modo, no es difícil observar que la enseñanza educativa es un acto de comunicación narrativo y de representación de la realidad, que puede apoyarse, a su vez, en otras formas narrativas, literarias o no, con contenidos reales o ficticios, y que pretende constituirse en un texto que genere sentido, cambios en los sujetos y, en ocasiones, impulse nuevos retos autobiográficos. La Narratología puede contribuir en esta dirección extendiendo no sólo el conveniente uso didáctico de las diversas formas narrativas sino también acercando el juicio educativo de los educadores a la consideración, no estudiada todavía en todas sus implicaciones, de que nos educamos narrativamente. 
La "narratividad" puede tener más interés aún para el ámbito pedagógico si observamos que no es una propiedad de los textos sino de nuestras posibilidades de pensar y sentir como humanos. En efecto, como señaló Hardy, lo narrativo no es una floritura estética del arte y las humanidades sino “(...) un acto primario del pensamiento transferido al arte desde la vida (...) soñamos narrativamente, recordamos, anticipamos, esperamos, nos desesperamos, creemos, dudamos, planeamos, revisamos, criticamos, construimos, cotilleamos, aprendemos, odiamos y amamos narrativamenten (HARDY, 1975, p. 5). Del mismo modo, para David Carr lo narrativo "(...) no es sólo un modo de organizar nuestras experiencias o la de los otros sino el mismo sustrato de la experiencia y de la construcción del yo" (CARR, 1986, p. 64; cursiva del autor).

Paul Ricoeur es el autor que, a mi juicio, ha estudiado mejor estos temas. Una de las tesis básicas de su monumental obra "Tiempo y narración", estriba en señalar que la comprensión de sí mismo es narrativa en su totalidad. Comprenderse es apropiarse de la historia de la propia vida de uno porque "la experiencia temporal tiene una narratividad incoativa que no procede de la proyección de la literatura sobre la vida, sino que constituye una auténtica demanda de narración" (RICOEUR, 1987, Tomo I, p. 148). No estamos, pues, principalmente, ante una forma de escritura, sino ante una forma de conocimiento, de conocer el mundo y, sobre todo, de conocernos (cfr. BRUNER, 1988, pp.24-25; vid. 1990; LÓPEZ-BARJAS, 1996; MAHABIR, 1997; GIL CANTERO, 1997) ${ }^{4}$. De este modo, la narratividad nos permite no quedarnos en el análisis semiótico de las diversas estructuras narrativas -enfoque con cierto interés, sin duda, pero de escasa relevancia pedagógica-, sino aventurarnos también en la dimensión crítico-ideológica, comprometida y transformadora de la realidad educativa.

Cuando los profesores se animan a escribir o relatar sus experiencias profesionales y personales; cuando fomentan, a su vez, que los alumnos escriban lo que les pasa o que cuenten cómo se sienten en el proceso de aprendizaje, están favoreciendo su formación, esto es, las experiencias de cambio, de crecimiento y, en su caso, de desarrollo profesional. Debido a estas razones es fácil explicar por qué dentro de los estudios narrativos, lo relativo a las narraciones autobiográficas, las historias de vida o los relatos o anécdotas autorreferenciales estén pasando a ocupar un lugar destacado en la educación. En efecto, el conjunto de acciones que de suyo conforman el acto de comunicación narrativo por excelencia (aquél en el que expresa la posibilidad de adoptar un punto de vista sobre la realidad en la que vivo y trabajo, aquél en el que se favorece la construcción de la identidad personal), lo constituyen los acontecimientos reales e incluso imaginados de nuestra propia vida.

4. Ya nos enseñó Ortega y Gasset que “(f)rente a la razón pura físico-matemática hay, pues, una razón narrativa. Para comprender algo humano, personal, o colectivo es preciso contar una historia. Este hombre, esta nación hace tal cosa y es así porque antes hizo tal otra y fue de tal otro modo. La vida sólo se vuelve un poco transparente ante la razón bistórica. (ORTEGA y GASSET, 1983, p. 40, cursivas del autor). 
Quienes hayan practicado el saludable ejercicio de redactar un diario personal estarán comprendiendo perfectamente estas distinciones. Esperar a que se apague el día, encontrar un lugar en la casa en el que estemos solos, encender una pequeña luz y escribir lo que hemos estado siendo, sintiendo y pensando en todo lo que hacíamos es, en efecto, una de las actividades constitutivas de la identidad personal. Como nos recuerda el profesor Emilio Lledó “(...) lo que somos no es tanto la estructura física que como cuerpo nos constituye, cuanto ese mensaje que el hombre ha ido forjándose en sí mismo, que acabará constituyendo su carácter, su ser, y que, efectivamente, como mensaje es un logos, o sea, una forma de decir, una forma de manifestación, de expresión... Pero el monolítico conglomerado de ese logos, o sea, de esa forma de ser, se hace lenguaje que crea una peculiar estructura ontológica: somos no sólo lo que bacemos, sino originariamente lo que decimos" (LLEDÓ, 1994, pp. 234-235; cursivas del autor). Por eso dirá también María Zambrano que "(s)e puede morir aún estando vivo (...) cuando a nadie le podemos contar nuestra historia" (ZAMBRANO, 1989, pp. 15-16).

Por lo que hemos visto, podemos afirmar ya que la narración autobiográfica es una forma particular de narrativa dirigida a contarnos a nosotros mismos y, en su caso, a los demás los significados y sentidos de los acontecimientos que hemos vivido. Amos Hatch y Wisniewski caracterizan el concepto de "narraciones autobiográficas" señalando que se refieren a un solo individuo; las unidades de análisis son las vidas individuales contadas a otros; se enfatiza la subjetividad y la escucha del otro; no siempre incluyen el relato del contexto pero, si lo hacen, se expresará como parte de la vida del sujeto y no para la explicación de conceptos ni la expresión de periodos históricos (cfr. AMOS HATCH y WISNIEWSKI, 1995, p. 116).

Geert Kelchtermans, con una perspectiva más centrada en los fundamentos, afirmará que la narración autobiográfica en educación «(...) en tanto que enfoque teórico está caracterizada por cinco supuestos generales. Es narrativa, constuctivista, contextualizada, interactiva y dinámica" (KELCHTERMANS, 1993, p. 443). El componente "narrativo" es el principal y con él pretende referirse "al énfasis sobre lo subjetivo (...). Esto implica, dice Kelchtermans, que la aproximación autobiográfica no se centra tanto en los hechos, sino más bien sobre los significados que ellos tienen para los hablantes" (KELCHTERMANs, 1993, p. 444). Para este autor "la enseñanza es una profesión artística en la que la incorporación del conocimiento experiencial es más importante que el conocimiento técnico-conceptual» (1993, p. 443). M. Grumet concreta algo más estas propuestas al señalar que, en su trabajo de formación del profesorado, recurre a las autobiografías guiadas para lograr que los docentes relacionen el currículo con sus experiencias educativas. Su finalidad estriba en que los profesores descubran sus intereses personales ocultos, así como los posibles prejuicios e ideas irracionales para volver a conceptualizar sus vidas y experiencias formativas (vid. GRUMET, 1981).

La última distinción conceptual que vamos a emprender es la relacionada con lo que se conoce como "referencia de los textos autobiográficos" que remite, a su vez, a la discusión en torno a la relación entre "autoría" y "VOZ" de las narraciones 
autorreferenciales. En esta ocasión, no podemos pasar a establecer una serie de definiciones en la media que con respecto al término "referencia" se abren varias interpretaciones filosóficas. Si recurrimos a nuestra experiencia y al sentido común lo lógico sería pensar que si un alumno o un educador redactan una autobiografía sobre su vida, la referencia del texto estará constituida por la vida del autor y, en su caso, su entorno. Y, en efecto, así es, pero no del todo. Puede ocurrir que el marco de interpretación que esté utilizando ese alumno o docente sea una referencia que en vez de favorecer la apropiación de su identidad personal, promueva un mayor distanciamiento autobiográfico e incluso una dispersión del sentido de sí mismo y de su mundo 5 . Todo en principio nos es ajeno y, sin embargo, desarrollarnos como seres humanos significa, entre otras cosas, aprender a apropiarnos, aprender a ser más nosotros mismos en la posesión de la realidad. "Tener lógos, dice Lledó, significa, entre otras cosas, algo más que la mera posibilidad de hablar, de comunicar una forma de ser a otros seres. Tener es, además y principalmente, una forma de posesión, y esa posesión es nuestra suprema sustancialidad; pero una sustancialidad siempre "posible", siempre abierta y, por tanto, en incesante proceso de creación" (LLEDÓ, 1994, p. 235; cursivas del autor). Frente a esta empresa, unas veces, nos sentiremos cerca y, otras, lejos de lo que consideramos una vida auténticamente lograda.

Pues bien, desde el campo de la Narratología, este proceso se entiende como la búsqueda de una referencia narrativa, de un horizonte, que haga las veces de brújula para que sepamos establecer y, en su caso, retomar las aspiraciones sobre nuestra identidad. Este proceso es también, desde en este enfoque, la trayectoria de la construcción de nuestra propia voz, a diferencia de la de los demás y, de igual modo, el descubrimiento de la autoría real de nuestras vidas. Y es aquí, donde, como decía, se abren diversas interpretaciones filosóficas con las que comenzamos el siguiente apartado de este artículo. Pero antes de exponerlas, querría situar esta discusión en su vertiente pedagógica.

Como hemos visto hasta aquí, las prácticas autobiográficas de los profesores y las explicaciones teóricas de las mismas apuntan ulteriormente a que, a través de su ejercicio y reflexión, pueden favorecer la adopción de significados o sentidos sobre la tarea educativa; o bien, se dirá, promover la elaboración de puntos de vista. No cabe duda de la importancia que tienen estas propuestas. Un buen educador tiene que saber establecer una perspectiva sobre su tarea. Sin embargo, no nos engañemos, el que las prácticas autorreferenciales favorezcan la determinación de un punto de vista poco garantiza la mejora de la práctica educativa. También adopta algún sentido el docente que se escuda en rutinas y en la mentalidad domi-

5. Esta distinción es recogida también por Hunter McEwan para referirse a las "narraciones coercitivas" y las "narraciones emancipatorias" (cfr. McEWAN, 1997, pp. 87-89). Para una exposición del uso teapeútico de las narraciones autobiográficas ("narraciones de estabilidad") puede consultarse la interesante discusión de K. J. GERGEN (1996, cap. X). 
nante del momento en que vive. Lo que pretendemos es que los educadores adopten mejores puntos de vista, perspectivas de mayor excelencia y, para este fin, es necesario que las narraciones autobiográficas partan de un marco valorativo que permita comparar, enjuiciar y divisar posibilidades mejores de la teoría y de la práctica educativa. En definitiva, se trata de observar que, como señala Gergen, "un relato (autobiográfico) no es simplemente un relato (autobiográfico). Es en sí mismo una acción emplazada, (GERGEN, 1996, p. 301, cursiva añadida).

Asumir plenamente las ideas anteriores supone aceptar, ulteriormente, que desde una perspectiva pedagógica, tal vez no valgan por igual todos los relatos autorreferenciales. Para muchos investigadores en el uso de la pedagogía narrativa esta afirmación es contradictoria en la media en que nos enfrenta ante un interrogante de difícil solución: ¿cómo podemos valorar las autobiografías de los educadores si lo propio de éstas es que recojan y relaten las particularidades de vida de cada uno:?

\section{AUTORÍA E IDENTIDAD EN LOS TEXTOS AUTOBIOGRÁFICOS}

Los movimientos actuales sobre estos temas en el pensamiento filosófico se sitúan en torno a dos corrientes opuestas: o bien se considera que lo narrativo es una propiedad del texto como planteará el estructuralismo lingüístico y su expresión más reciente en la gramatología de Jacques Derrida, o bien se piensa que lo narrativo es una propiedad inherente de la acción humana como defenderá la hermenéutica de Paul Ricoeur y, en otro sentido, Alasdair Macintyre.

Para Derrida la importancia de los textos está en los mismos signos y no en que éstos remitan a un sentido, una verdad o una razón. Según este autor, la cultura occidental se encuentra encerrada en la perspectiva hermenéutica, según la cual tendemos a pensar que detrás de cada texto hay un sentido último, una verdad o una falsedad que tenemos que descubrir, una "metafísica de la presencia". Para Derrida hay que oponerse a esta tendencia, pues nada hay fuera de los textos, e iniciar el proceso de lo que ha llamado la deconstrucción o desargumenta-

6. Otro modo de plantear este problema en términos más relacionados con la validación epistemológica de los relatos autobiográficos estriba en desentrañar y, en su caso, salvar, el concepto de verdad narrativa. Véase el interesante modo en que lo plantea GARY D. FENSTERMACHER (1997) tratando de armonizar las tesis opuestas de D.C. PHILLIPS y de W. DOYLE. Por mi parte considero que la discusión relevante, desde la educación y para el tema que nos ocupa, no estriba en saber si los acontecimientos narrados se ajustan o no a lo realmente vivido, sino las implicaciones (responsabilidades) éticas que se derivan de las acciones; implicaciones que, por cierto, no desaparecen ni en los personajes de ficción. Por eso, la narración autobiográfica es absolutamente libre, desde la literatura, para dar con una forma textual, pero no lo es de igual modo, desde la educación, en relación con el reconocimiento de las posibilidades humanizadoras de las acciones y, por tanto, con el diferente valor educativo de unos modelos o de otros. Si renunciamos a esto nos quedamos sin Pedagogía o, para ser más precisos, con una literatura novelada de la Pedagogía, esto es, con la máscara retórica del sobresalto sentimental o poético de las palabras. 
ción de los sentidos vistos con anterioridad al texto, para lograr quedarnos, dirá, con el sentido inmanente al propio signo. Desde esta perspectiva, leer o escribir no supone tener que alcanzar algún último sentido verdadero. Ahora bien, cabe preguntarse, ¿qué ocurre una vez realizado, si se puede, ese proceso de deconstrucción? Para Derrida cuando el lector o escritor realiza ese proceso lo que consigue es encontrarse con la referencia estética de los signos que, ahora sí, despertará con mayor o menor fuerza la voluntad de sentido del lector o escritor, por lo que todos los sentidos que puedan hallarse son igualmente legítimos. La referencia del texto será así un gesto sentimental y emotivista en la recepción de la lectura o escritura que "ofrecerá" sentidos e interpretaciones en función de los estados subjetivos del lector o escritor.

Como afirma Derrida en su libro "Márgenes de la Filosofía", "(1)a escritura se lee, no da lugar, 'en última instancia', a un desciframiento hermenéutico, a la clarificación de un sentido o una verdad" (DERRIDA, 1994, p. 371). Cuando el texto es nuestra autobiografía, entonces, la actividad constitutiva de la identidad ha de empezar por la deconstrucción como proceso de desidentificación: aprender a vernos sin ninguna referencia estable. Por eso dirá Derrida que somos un "devenirausenten: un proceso de ser sin referencia estable. Como en la tendencia postmoderna hay, pues, una dispersión de la subjetividad, que trasmite un sentido huidizo e inaprensible de la existencia.

Una de la influencias básicas del estructuralismo en el pensamiento filosófico es el reconocimiento de que el hombre no puede seguir concibiéndose a sí mismo como sujeto, dueño de sí mismo y de su mundo. Influencia que en clave postmoderna se extiende a una clara disolución de la subjetividad, identidad y razón humana. En efecto, si alguna ventaja está teniendo la imparable producción bibliográfica sobre postmodernidad estriba en que se está llegando a un gran acuerdo acerca de algunos síntomas peculiares de nuestra época. Muchos autores coinciden en destacar que nos encontramos inmersos. en concepciones de valores individualistas que tienden a concebir al hombre como un "microcosmos" autosuficiente. Estas actitudes serían para algunos ma consecuencia inevitable, por un lado, del carácter esencialmente fragmentado, huidizo y cambiante de la vida y, por otro, del derrumbe de las ideologías, de las comprensiones globales de la realidad y, ulteriormente, de la pérdida de la esperanza de encontrar alguna verdad estable. Pues bien, no cabe duda que estas tendencias se encuentran también de algún modo en el origen y sentido que se atribuye en ocasiones a las narraciones autobiográficas en educación, pues éstas apoyarían, como otros fenómenos sociales, la tesis de la "muerte de los grandes relatos" y su sustitución por las historias individuales.

Ante un futuro incierto, se dirá, sólo. cabe el asidero del relato de la propia vida como medida de certidumbre. "Hemos aprendido, dice José Jiménez, que el hombre no es, deviene: somos ante todo, transformación, metamorfosis (...) Reivindicar hoy la memoria no significa pretender, ingenuamente, volver a la ilusión de un 'gran relato'. Pero sí tomar consciencia de los 'los relatos' operativos (...) Naturalmente, no en términos de sustantividad y homogeneidad, sino de formati- 
vidad y pluralidad. Somos 'prosa' al tiempo que 'poesía': relato y metáfora, memoria y exploración" (JIMÉNEZ, 1989, pp. 24-25).

Desde estas ideas cualquier debate acerca del papel del hombre como actor o autor es algo más sustantivo y determinante que una mera metáfora literaria. Nos encontramos ante toda una concepción de la condición humana y ante una imagen de futuro de lo que el hombre es y debería llegar a ser. Vivir, se dirá, no es lograr una identidad sino en la línea de los llamados deconstruccionistas asumir la esencial desidentificación del hombre. Somos pura transformación, una metamorfosis permanente por lo que vivir y vivir con sentido es el relato ulterior de una elección. "Crecientemente -afirma Jiménez- nos vemos a nosotros mismos como actores que, en el escenario del mundo, no interpretamos un papel único. Podemos ser compasivos o crueles, tiernos o duros, formales e informales y, en fin, femeninos o masculinos, según la situación y los demás participantes de la escena que vivimos. Somos una metamorfosis continua, y cada vez nos hacemos más conscientes de ello" (JIMÉNEZ, 1989, p. 192). Gergen se pregunta y se contesta de igual modo: "¿Se reduce el individuo a ser un estafador social, adoptando cualquier postura de identidad que recoja la mayor recompensa? (...) Desde el punto de vista construccionista, la relación adquiere prioridad sobre el yo individual: los yoes sólo se realizan como subproductos de la relación. Por consiguiente, cambiar la forma y el contenido de la autonarración de una relación a otra, no es ni fraudulento ni egoísta en el sentido tradicional. Más bien es honrar los diversos modos de relación en los que uno está cogido" (GERGEN, 1996, p. 303).

Desde estas ideas puede entenderse mejor el fundamento que, para algunos, tendría la propuesta de acentuar lo autobiográfico o autorreferencial en cualquier tipo de experiencia humana, incluida, claro está, la educación. Somos, se ha dicho, una metamorfosis, por lo que podemos ser cualquiera de los autores y actores que nos pueblan, y ese poder-ser será el relato de una elección. Dicho en pocas palabras: todo vale, toda elección es valiosa porque todo es ulteriormente narrable como una historia de vida particular ${ }^{7}$. Podría darse así en las prácticas autobiográficas de los docentes y de los alumnos un cierto narcisismo pues el proceso de vivir pasaría a proclamarse la obra final misma, la autocomplacencia en el relato elegido. Los procesos quedarían legitimados en su misma transformación. Por eso, defenderá de nuevo Jiménez que "(...) el proceso (es) lo que permite alcanzar alguna luz, y no el producto final. Es la transformación en el proceso de realización de la obra, y no la obra misma: abierta y nunca conclusa, lo que interesa al protagonista humano" (JIMÉNEZ, 1989, p. 170).

7. Que los procesos de individualización y privacidad se sobrevaloren en contextos sociales fuertemente relativistas es una consecuencia lógica. En efecto, todo abandono de la aspiración a modificar sustancialmente la realidad, presente en cualquier perspectiva relativista, lleva consigo también que los proyectos terminen asentándose sobre el giro que da el sujeto sobre sí mismo. 
En relación con estas ideas, considero que si a lo que se refieren los autores citados y, en general, la corriente de pensamiento que representan, es a los cambios en los diversos roles sociales y familiares que mantenemos, nada hay que objetar. Si a lo que se refieren es a las diversas posibilidades de elaboración de la identidad narrativa, tampoco habría nada que cuestionar. Otra cosa bien distinta es si nos referimos al conocimiento de sí mismo y a las relaciones que mantenemos con los demás. Es llamativo que la dificultad para armonizar el cambio y la permanencia lleve a algunos a aplaudir la adopción de un "yo camaleónico", como en la divertidísima película de Woody Allen en la que el protagonista, para agradar, va adquiriendo hasta físicamente las diferentes identidades de sus diversos interlocutores. Desde las posturas señaladas, poco podrían decir los autores citados si, por ejemplo, en una supuesta autobiografía de Pinochet, éste considerase que sus "torturas" se basaban en querer desarrollar la industria chilena. Como veremos más adelante, Ricoeur establecerá una sutil diferencia ente la identidad narrativa y la ipseidad, centrándose en la responsabilidad ética del autoconocimiento. Charles Taylor criticará de igual modo esas tesis afirmando: "(m)e gustaría definir esto como el yo 'neutro' o 'puntual'. 'Puntual' porque el yo se define abstrayendo de cualquier inquietud constitutiva y, por tanto, de cualquier identidad (...) Si consideramos el yo como neutro, entonces, quizá tenga sentido sostener que el cómo nos consideramos a nosotros mismos en última instancia es una cuestión arbitraria (TAYLOR, 1996, p. 66, cursiva añadida). De igual modo, para MacIntyre, "(e)ste yo democrático, que no tiene contenido social necesario ni identidad social necesaria, puede ser cualquier cosa, asumir cualquier papel o tomar cualquier punto de vista, porque en sí y por sí mismo no es nada" (MAcINTYRE, 1987, p. 51; cursiva del autor).

Puede ser interesante abrir un paréntesis en este momento para mostrar cómo el enfoque presentado tiene su expresión en numerosos fenómenos sociales, en concreto, y para no alejarnos demasiado de nuestros objetivos en la literatura autobiográfica. No se trata de apartarnos de los intereses pedagógicos pero tampoco de considerarlos aisladamente. En casi todos los casos imaginables, la educación participa (ampliando, transformando o simplificando) cierto espíritu de los tiempos y la literatura autobiográfica es un buen ejemplo de este proceso de contagio.

No deja de ser significativo que el producto por excelencia de las editoriales, el que abre mayor cota de mercado en la actualidad, sean las autobiografías y no precisamente las de grandes personajes sino los de pañuelo y pandereta. E incluso que en relación a importantes escritores se lean más sus diarios que sus propias obras. Günter Grass se ha referido a este fenómeno, que atribuye a la cultura postmoderna, con la expresión: "dictadura de lo secundario". Según el escritor alemán en la actualidad a la mayoría de los lectores y de las editoriales, pero lo que va a afirmar podría valer como él mismo señala a casi todos los ciudadanos con sólo pasar de la literatura a cualquier ámbito de la cultura, lo que les interesa no es la obra misma de los grandes escritores sino los diarios ya sean los realmente escritos por los autores o los reconstruidos por advenedizos oportunistas. Lo que interesa, dirá Grass, es averiguar lo secundario: ¿con qué mano escribía?; ¿tuvo alguna 
amante? ¿dónde pasaba sus ratos de ocio? ¿era géminis o capricornio? (cfr. GRASS, 1994, pp. 9-10) ${ }^{8}$. En este sentido, el escritor Antonio Muñoz Molina comentando en una entrevista las principales dificultades a las que tuvo que enfrentarse en la elaboración de su libro "Ardor Guerrero" -texto basado en su experiencia sobre el servicio militar-, destaca la de permanecer bajo la intención de tomar como punto de partida la experiencia personal y no la experiencia egocéntrica o intimista que, según él, está inundando las diversas manifestaciones de la cultura (cfr. MUÑNOZ MOLINA, 1995, p. 4).

Puede ser interesante del mismo modo observar que el auge que en nuestro país está teniendo lo que se ha dado en llamar la "nueva narrativa española" ha basado su éxito, entre otras razones, en adoptar como género literario la "ficción biográfica". Ésta consiste, según Javier Marías, en que el autor sin advertir o afirmar en ningún momento que los materiales usados en su relato son autobiográficos, intenta por todos los medios a su alcance dar a su obra el aspecto de una confesión en la que el narrador recuerda claramente al autor en la coincidencia de determinados hechos bien porque éstos están recogidos en la contraportada del libro, o bien porque se asemejan a la imagen que de él se tiene a través de los medios de comunicación (cfr. MARÍAS, 1993, p. 68).

El resultado consiste en provocar en el lector la idea de que el autor es, en realidad, un personaje más de sus propias obras, al que hay que seguir a todas partes, en todos sus textos y declaraciones públicas para conseguir descubrir si en verdad lo relatado le ha sucedido al autor. Como afirma Javier Marías «el resultado de este malabarismo es de una ambigüedad tan asombrosa que las sospechas del lector oscilan de continuo entre dos polos o tendencias opuestas, sin que pueda decidirse por ninguna de ellas". Este tipo de escritor, continúa Marías, "al presentar su texto como ficción pero no hacer nada para ficcionalizarlo, lo que quizá está haciendo es indicar ambas cosas a la vez" (MARÍAS, 1993, p. 63). En cualquier caso, lo que se pretende trasmitir es una idea y una imagen lo más ambigua posible de la propia identidad, como en los juegos de roles, en la que todo relato podría ser o no verdad. Esta es, por cierto, una característica muy extendida y analizada en las llamadas "novelas postmodernas". "Los lectores, dice Heise, no son capaces de decidir qué versión ( si la hay) corresponde 'realmente' con los sucesos que ocurren en el relato (...) Como consecuencia, también es imposible para el lector inferir una imagen coherente de las acciones que subyacen en las repeticiones (de

8. Javier Marías también ha criticado, con su peculiar ironía, la misma tendencia: "(e)n los últimos tiempos (...) no cesan de aparecer biografías de artistas y escritores célebres cuya única misión parece ser la contraria de la hagiografía, a saber: demostrar que todos y cada uno de ellos fueron unos miserables en su vida personal: ambiciosos, canallas, tiránicos, plagiarios, crueles, mezquinos, egoístas, explotadores, fatuos, sádicos (...). De la acusación póstuma de homosexualidad o impotencia no se libra hoy casi nadie (como si tales cosas fueran lacras)..." (MARÍAS, 1997, pp. 21-22). 
tiempos) dado que no hay criterios para evaluar la realidad de cualquier versión del texto que ocurre en el presente (HEISE, 1997, p. 56)9.

He indicado antes la presencia de dos corrientes filosóficas que pueden ayudarnos a comprender las posibilidades y límites de las narraciones autobiográficas en educación. Nos corresponde, pues, tras la gramatología de Derrida pasar a ocuparnos de la hermenéutica reflexiva de Ricoeur. Recordemos, brevemente, que estamos buscando diversas consideraciones en torno a la referencia de los textos autobiográficos, el concepto de autoría y el de voz narrativa.

Pues bien, la primera diferencia fundamental que hay que destacar es que si en Derrida, como hemos visto, y, en general, en toda la semiótica estructural se rechaza por postulado de método la idea de una referencia extralingüística, en la hermenéutica de Ricoeur hay una cierta presuposición ontológica de la referencia que no está primeramente en el texto, sino en la experiencia previa del hombre de estar en el mundo y en el tiempo, experiencia que ulteriormente llevamos al lenguaje. En esta perspectiva, la comprensión de una narración no es la comprensión del mundo estético del lenguaje, pues, dirá Ricoeur, "el lenguaje no constituye un mundo por sí mismo. Ni siquiera es un mundo" (RICOEUR, 1987, Tomo I, p. 154).

Aquí el lenguaje es sólo el signo de un sentido anterior y exterior a él. Pero, ¿cuáles son esos sentidos previos al lenguaje? Para Ricoeur son mundos, formas de vida o estilos de ser que el texto nos ofrece. "He defendido continuamente estos últimos años, dice Ricoeur, que lo que se interpreta en un texto es la propuesta de un mundo en el que yo pudiera vivir y proyectar mis poderes más propios" (RICOEUR, 1987, Tomo I, p. 158). El texto, por tanto, no es una sombra de la realidad sino una ventana con la propiedad de agrandar las posibilidades de la acción humana. Para este autor, narrar nuestra propia historia de vida estriba en emprender una interpretación práctica consistente en presuponer un orden de sentido y transformarnos con él. Nos estamos refiriendo, pues, a una referencia reconocida y reconstruida. A través de la escritura autobiográfica no hacemos sólo presente las acciones pasadas sino que las valoramos porque "(n)o hay acción que no suscite, por poco que sea, aprobación o reprobación" (RICOEUR, 1987: Tomo I, p. 127).

La sobrevaloración estructural de los textos y, por tanto, la pérdida de referencia práctica-moral de una historia de vida, lleva a la paradoja de que lo que debería servir como vehículo para esclarecer nuestra identidad, impide, sin embargo, esta posibilidad. En efecto, quedarnos en el texto autobiográfico como un fin en sí mismo, como signos o palabras intercambiables, supondría dar un

9. Me parece ocioso advertir que no pretendo descalificar este tipo de literatura. Lo que he querido mostrar, como señalaba al principio, es que las bases filosóficas de algunas corrientes no son meras ideas académicas sino que, en cierto modo, tienen su particular expresión en otros fenómenos sociales. Fenómenos que, cuando procede, la educación debe considerar. Así, por ejemplo, para Gergen el creciente interés por vincular la Filosofía y la Literatura tiene su explicación en que ésta es hoy el producto cultural que mejor está mostrando el empuje estético de la postmodernidad (cfr. GERGEN, 1996, pp. 60-61). 
enfoque tan individualista, particular y privado a toda narración sobre nosotros mismos que estaríamos alterando profundamente la representación mimética con la interpretación valorativa de las acciones, lo que nos llevaría a la paradoja de que mientras parece crecer el significado para nosotros ("mi texto", "mi mundo", "mi vida") estaría ocultándose, sin embargo, para los demás y, ulteriormente, para todos en una gran representación falseada de la creatividad al dejar intacta la mediación simbólica de toda acción originariamente vinculada a una interpretación de lo bueno y lo malo (cfr. RICOEUR, 1987, Tomo I, 122-126). Lo que ulteriormente ha de descubrir toda experiencia al ser compartida es que "tiene al mundo por horizonte", "el horizonte de un mundo total, el cual no figura nunca como objeto de discurso" (RICOEUR, 1987, Tomo I, pp. 153-154). Además, ese mundo está constituido por formas de vida que se viven en común, por lo que los relatos autobiográficos, cuando se abren a los mundos posibles, se están abriendo en realidad a una vida humana en interacción y diálogo con otras (cfr. RICOEUR, 1999, Tomo III, p. 150$)^{10}$. Recordamos para comunicarnos más y mejor con los demás.

Esta es la posición de Ricoeur frente a lo que considera excesos estructuralistas en la comprensión narrativa de los textos. En relación con el problema de la identidad en la narración autobiográfica, Ricoeur considera que la identidad de los sujetos solo puede comprenderse y alcanzarse como una identidad narrativa, ya que es ésta la que permite incorporar los cambios en la persona a lo largo del tiempo pero evitando también la visión del hombre como una amalgama dispersa y arbitraria de cogniciones, emociones y voliciones (cfr. RICOEUR, 1996, Tomo III, p. 997). La identidad y la narración se vinculan conceptualmente y en la práctica al considerar, según Ricoeur, que la primera descansa sobre la composición dinámica y cambiante de un texto narrativo. El sí mismo se configura en el conocimiento narrativo de mis propios cambios, no en la ilusión sustancialista de los mismos: sigo siendo yo porque soy yo quien, como agente, examino mi vida, la purifico y clarifico. $Y$ en este examen, "la historia de una vida es refigurada constantemente por todas las historias verídicas o de ficción que un sujeto cuenta sobre sí mismo". Mi identidad es el resultado del examen de la cohesión de mi vida: "un sujeto, dice Ricoeur, se reconoce en la historia que se cuenta a sí mismo sobre sí mismo" (RICOEUR, 1996, Tomo III, p. 998 y 999 respectivamente).

En el marco de estos análisis filosóficos vamos a analizar también las ideas de Alasdair MacIntyre en quien encontramos casi las mismas distinciones que en los trabajos de Ricoeur. Antes de nada conviene señalar que para MacIntyre es urgente superar los conceptos modernos de identidad y de acción humana que reducen el yo a un puro decisionismo y emotivismo, y situarlos de nuevo en la perspectiva de

10. Valdecantos lo explica también acertadamente cuando señala que "(q)uien no ha visitado nunca la comarca del sujeto construido lo ignora todo sobre sí mismo; quien pretende vivir en ella está condenado a tener que abandonarla precipitadamente; sólo quien ha aprendido a combinar la perspectiva comarcal con el punto de vista del agente puede aspirar a una cierta lucidez sobre el significado de sus acciones..." (VALDECANTOS, 1996, p. 218). 
una tradición heredada, de un orden y sentido de vida que no encuentra sólo su origen en la deliberación individualista del sujeto. Para el autor de "Tras la Virtud" la identidad personal debe considerarse "una clase de unidad de vida", y esta unidad no es la mera elección de un relato o narración que relacione mejor o peor las intenciones y las circunstancias vividas. Alcanzar una unidad de vida, por el contrario, es lograr "algo" frente a otras opciones, narraciones o relatos: es alcanzar la vivencia de la virtud y el reconocimiento experiencial de vernos situados en una tradición. Veamos estas ideas más detenidamente.

Para MacIntyre, la narración no es sólo una forma de explicación, ni mucho menos un adorno o un disfraz de nuestras vidas. En este autor, la narrativa es un rasgo esencial del ser humano porque constituye la estructura básica de la vida y, por tanto, de la identidad personal. Por eso, en su conocido texto aparecen numerosas veces estas dos ideas complementarias: primero, que la forma narrativa es la apropiada para entender las acciones de los otros porque todos nosotros vivimos y entendemos narrativamente nuestras vidas (cfr. MAcINTYRE, 1987, p. 261) y, en segundo lugar, que el hombre es una narrativa encarnada (cfr. MAcINTYRE, 1987, p. 269). Para MacIntyre la narrativa nos permite vincular los acontecimientos de nuestra vida en un relato y, por tanto, nos es necesaria para la configuración de nuestra identidad. Ahora bien, ese relato aunque, según este autor, pueda darnos la impresión, desde la tradición ilustrada, que es una elección o un producto exclusivo de nuestra deliberación, en realidad, considera MacIntyre, puede descubrirse entre todas las posibilidades, una narrativa, un relato, más correcto en el sentido de que caracteriza mejor nuestra unidad de vida.

De este modo, la pregunta por mi identidad personal no es el efecto o resultado de lo que ha acontecido, sino al revés: me van ocurriendo sucesos y voy eligiendo caminos en función de mis nociones sobre las prioridades de los bienes diferentes. Para MacIntyre el concepto y el sentido de la narrativa se construye desde el de la virtud. Una vida lograda será así llegar a reconocer el orden narrativo, el orden virtuoso que la vida manifiesta. Por eso, afirmará que "(...) tomar postura acerca de las virtudes será tomar postura acerca del estilo narrativo que más cuadra a la vida humana" (MAcINTYRE, 1987, p. 182) ${ }^{11}$.

Para MacIntyre, ese orden no depende enteramente, como hemos señalado, de la deliberación del sujeto. "En la vida (...) (e)ntramos en un escenario que no hemos diseñado y tomamos parte en una acción que no es de nuestra autoría" (MAcINTYRE, 187, p. 263). Los sujetos, para MacIntyre, no son en rigor autores de sus narraciones sino coautores de una narración inserta en una tradición. "(1)a pre-

11. "Si la vida humana se entiende como un tránsito a través de daños y peligros, morales y físicos, a los que uno se enfrenta y vence peor o mejor y con mayor o menor éxito, las virtudes encontrarán su lugar como cualidades cuya posesión y ejercicio conducen al éxito en la empresa y los vicios, a su vez, como cualidades que llevan al fracaso. Por tanto cada vida humana encarnará una historia cuya forma y configuración dependerán de lo que se tenga por daño y peligro, por éxito y por fracaso, progreso y su opuesto, en fin de cómo se entiendan y valoren" (MAcINTYRE, 1987, p. 182). 
gunta clave para los hombres no versa sobre la autoría; sólo puedo contestar a la pregunta ¿qué voy a hacer? si puedo contestar a la pregunta previa ¿de qué historia o historias me encuentro formando parte? Entramos en la sociedad humana con uno o más papeles-personajes asignados, y tenemos que aprender en qué consisten (..)" (MAcINTYRE, 1987, p. 266). De este modo, referirnos a la conquista de la identidad personal supone, para MacIntyre, conquistar la identidad "presupuesta por la unidad del personaje".

En definitiva, en MacIntyre encontramos que la aceptación de una referencia de orden previa a la narración del sujeto es la condición de posibilidad de compartir y vivificar una común comprensión práctica que ulteriormente remite a la idea de una unidad de vida auténticamente lograda. Para MacIntyre, alcanzar una unidad de vida supone en concreto alcanzar «(...) la unidad de un relato de búsqueda (...) una búsqueda siempre es una educación tanto del personaje al que se aspira, como educación en el autoconocimiento" (MAcINTYRE, 1987, p. 270).

Siguiendo con nuestros análisis filosóficos, vamos a terminar este apartado exponiendo algunas propuestas de Hanna Arendt y de Charles Taylor. Para Arendt, "(s)ólo podemos saber quién es o era alguien conociendo la historia de la que es su héroe, su biografía, en otras palabras, todo lo demás que sabemos de él, incluyendo el trabajo que pudo haber realizado y dejado tras de sí, sólo nos dice cómo es o era" (ARENDT, 1993, p. 210; cursiva de la autora). La pregunta decisiva para esta autora en torno a una persona no estriba en determinar qué es esa persona sino quién es. Mientras que con la primera cuestión, la persona queda reducida a un conjunto de atributos y cualidades que apenas alcanza a una cierta individualización, la segunda, en cambio, requiere atender a la historia personal, al yo producto de una vida narrada (cfr. ARENDT, 1993, p. 205-211).

Cuando exteriorizamos nuestra vida en un relato, la experiencia de descubrir el significado de lo que el mismo sujeto ya sabía que había hecho u omitido prueba, dirá Arendt, la experiencia de vivirse como protagonista de algo, de ser actor, pero al mismo tiempo la visión de ese horizonte nos hace reconocer que no somos autores. Por eso afirmará: "Aunque todos comienzan su vida insertándose en el mundo humano mediante la acción y el discurso, nadie es autor o productor de la historia de su propia vida. Dicho con otras palabras, las historias, resultados de la acción y el discurso, revelan un agente, pero este agente no es autor o productor. Alguien la comenzó y es su protagonista en el doble sentido de la palabra, o sea, su actor y paciente, pero nadie es autor" (ARENDT, 1993, p. 208).

El último autor del que vamos a ocuparnos es Charles Taylor. Para este filósofo, un rasgo ineludible de la vida humana es la determinación de la dirección de nuestras vidas. "He venido defendiendo que para encontrar un mínimo sentido a nuestras vidas, para tener una identidad, necesitamos una orientación al bien, lo que significa una cierta percepción de discriminación cualitativa, de lo incomparablemente superior. Ahora vemos que dicha percepción del bien ha de ir entretejida en la comprensión que tengo de mi vida como una historia que va desplegándose. Pero esto es manifestar otra condición básica para poder entendernos: 
hemos de asir nuestras vidas en una narrativa" (TAYLOR, 1996, p. 64). Para Taylor "Mi vida siempre tiene un grado de comprensión narrativa; yo entiendo mi acción presente en la forma de un 'y entonces': ahí estaba A (lo que soy), y entonces hago B (lo que proyecto llegar a ser)" (TAYLOR, 1996, p. 64).

La aportación más interesante de este autor para nuestros propósitos es que la autoría, la voz, o la identidad personal, no es la autoría, voz, identidad de lo que creo que soy yo, de mi autoconciencia, sino de la determinación en una orientación de conjunto hacia lo que piense que es el bien, la plenitud o el significado superior. Para este autor, entender nuestras vidas en forma narrativa es, en realidad, una condición secundaria frente a la orientación primera y esencial al bien. Más en concreto: pienso que para Taylor cabría la posibilidad de mantener al mismo tiempo la condición narrativa de nuestra vida y la concepción que él denomina "neutra" o "puntual" del yo. Taylor, como antes Macintyre, rompe la perspectiva psicologista de la identidad por vía de un yo como un ser que existe en relación con la aspiración a alguna forma de plenitud. La identidad, para este autor está definida por nuestras evaluaciones fundamentales, las cuales requieren alguna tipo de conciencia reflexiva de los criterios en los que estamos viviendo (vid. TAYLOR, 1994).

\section{LAS AUTOBIOGRAFÍAS EDUCATIVAS COMO "ESPACIOS DE INQUIETUDES"}

Las prácticas autobiográficas propuestas a los profesores pretenden mejorar su ejercicio profesional mediante la vinculación de dos factores: las experiencias de vida y la formación de la identidad. De entre los posibles modos de articular estos principios, la corriente narrativa autobiográfica optará por considerar que la entraña de las experiencias formativas en el ser humano se encuentra en el reconocimiento de nuestra autoría y voz en los acontecimientos vividos fuera y dentro del aula.

Para entender el alcance pedagógico de este supuesto conviene observar que no se le está proponiendo al docente la conveniencia de establecer una cierta visión normativa sobre el carácter educativo o formador de los acontecimientos vividos, lo que podría llevar a afirmar "esto puede formarme mejor como profesor y aquello otro no". Lo que se propone, por el contrario, es que el hecho mismo de vivir y, sobre todo, de alcanzar un sentido de autoría e identidad en esa vida es el acontecimiento formativo por excelencia. Esta propuesta me parece muy acertada pero insuficiente.

Es acertada porque una de las voces que menos se oyen en nuestra sociedad es la de los educadores. Su presencia en la vida social suele estar asociada a acontecimientos desagradables, a errores o a denuncias. Se les considera también, en no pocos casos, meros ejecutores de las políticas educativas, de la mentalidad dominante o de los deseos de los padres. Viven en situaciones contradictorias entre, por un lado, las peticiones para centrarse en los aspectos útiles o producti- 
vos del currículo y, por otro, las dirigidas a ofrecer una sólida base formativa. En algunos casos -basta con hablar con ellos- tienen miedo, miedo de los alumnos adolescentes, de los padres airados, de que les denuncien porque el niño o la niña se rompa unos pantalones nuevos en el recreo. Los docentes necesitan enfrentarse a su propia identidad profesional y, en su caso, personal; construirse una sólida voz con autoridad moral para advertir y criticar las equivocaciones políticas, sociales y familiares que dificultan e impiden la educación de las nuevas generaciones.

Las prácticas autobiográficas son así muy convenientes porque pueden favorecer una identidad más estable e independiente, que promueva, según las casos, un cierto sentido de "resistencia" y convencimiento sobre la importancia de su labor. Son muy necesarias también porque lo que los docentes precisan no son sólo aprendizajes de nuevas técnicas sino seguridad sobre sí mismos, sentido claro de la orientación de su labor y, sobre todo, compartir la idea de que su mejora profesional implica un permanente vigor de ánimo para mantenerse en una línea de desarrollo personal continuo. La experiencia autobiográfica de los docentes les puede permitir así recuperar la perspectiva esencial del saber práctico-educativo, esto es, que la primera tarea de todo docente que pretenda ser al tiempo un buen educador no estriba en especializarse en un saber hacer o en unas ideas determinadas sino en alcanzar, mantener y mejorar una forma de ser que con su presencia muestre a los alumnos lo que aspiramos a que éstos lleguen a ser. Saber ser, estar y proyectarse humanamente es la primera obligación de un educador.

Las prácticas autobiográficas tienen otro supuesto o base reflexiva de indudable valor formativo. Me estoy refiriendo al uso educativo de la memoria personal y profesional. En efecto, los docentes tienen un importante vehículo de formación a través de la memoria no ya de otros periodos históricos sino de su propia trayectoria personal y profesional. La memoria sobre lo que hemos hecho desde que iniciamos esta tarea, permite reafirmarse y revivir, actualizándolos, los compromisos personales hacia el logro del cambio personal y social en que consiste la educación. Como señala el profesor Bárcena, “(a) través de ella (de la memoria) nos enfrentamos, en el proceso de formación de nuestra subjetividad, a determinados acontecimientos del pasado acerca de los cuales tenemos que adoptar una actitud de responsabilidad determinada" (BÁRCENA, 1999, p. 3; vid. MÈLICH, 1998). La memoria permite también sentirnos culpables, esto es, no llegar a asumir que todo da igual y, por tanto, que podemos aquí y ahora hacerlo mejor. La memoria, en fin, nos permite convertirnos en investigadores de nuestra propia mejora profesional ${ }^{12}$.

Ahora bien, las prácticas autobiográficas pueden ser insuficientes si se conciben como experiencias egocéntricas, cerradas sobre sí mismas y sin ningún marco normativo. Las experiencias personales y profesionales son un buen punto de par-

12. En MITCHELL y WEBER (1999) se recogen para la misma finalidad la visión de álbumes de fotos escolares, dibujos, diarios, juegos infantiles, visionado de videos, películas sobre profesores, anécdotas, etc. 
tida pero no de llegada si se acaban en sí mismas. En las propuestas educativas la entraña se encuentra, a mi juicio, en los horizontes de valor que divisamos y el empeño consiguiente por alcanzarlos.

Nos podemos encontrar así, a mi juicio, con un cierto desequilibrio entre el orden de realidad que trata de delimitar la Pedagogía y el que pretenden determinar algunos enfoques narratológicos. En efecto, la difícil búsqueda de los fines posibles de la persona en tanto que humanizadores puede estar siendo relegada por una condición de posibilidad, muy importante, nadie lo puede negar, pero previa: que todo en nosotros, lo educativo y lo menos formativo, lo bueno y lo menos bueno, es narrable y siempre es posible encontrar una autoría, una voz, un relato, un viaje inacabado, una lucha, una trama. Esta inversión de órdenes es la que podría explicar una de las impresiones más comunes que provoca la lectura de algunos de los trabajos de esta línea de investigación: a veces parece que se confunde la acertada y necesaria construcción de una metáfora narrativa de la educación con una mera metáfora educativa de la narración.

Las narraciones autobiográficas permiten al docente adoptar una clara posición de agente pero no necesariamente de agente educativo ${ }^{13}$. Adoptar un punto de vista, establecer un sentido unitario y coherente de los acontecimientos vividos, emprender una seria reflexión sobre su labor, son logros iniciales básicos para quien pretenda mejorar su marco profesional y personal. Pero si bien son propuestas muy extendidas en el ámbito pedagógico, son expresiones huecas que pueden terminar favoreciendo un mero círculo hermenéutico mientras no se apoyen en otras nuevas direcciones y propósitos. Por eso creo que pueden ser de cierto interés algunas de las ideas de la discusión filosófica sobre la referencia de los textos autobiográficos, así como su aplicación a los conceptos de voz y autoría.

Parece claro que la identidad humana es una identidad narrativa que, como tal, incluye el cambio y la diferencia pero también la permanencia del sí mismo en la diversidad. Sin embargo, por lo que hemos visto, tal vez la identidad personal sea un problema práctico-moral porque si bien mi identidad la logro narrando, el conocimiento de si mismo que alcanzo no se expresa en todas sus posibilidades en lo que narro o me cuentan, sino en el modo en que valoro lo vivido y, sobre todo, en lo que decido hacer o dejar de hacer en el futuro, según mi pasado y las tradiciones con las que me encuentro, según el modo en que quiero reconocerme y el modo en que quiero poseer la realidad y a mí mismo en el mundo que me ha tocado vivir. Pues bien, lo interesante para nuestra perspectiva pedagógica es que esta última condición, constitutiva de la identidad, no es en rigor una condición

13 Hacemos esta distinción para acentuar la perspectiva pedagógica del argumento. Sin embargo, se podría llevar al extremo la afirmación apuntada en el sentido de que los sujetos podemos estar sustrayendo nuestra condición de agentes si lo autobiográfico se entiende como reconocimiento de un yo construido que me determina y justifica mis acciones. Siempre es posible reconstruir imaginariamente el pasado para encontrar el hilo conductor que me exima de toda responsabilidad en mis acciones presentes y futuras. 
narrativa sino ética. Es aquí donde, por cierto, encontramos los límites que el propio Ricoeur pone a la dimensión narrativa de la identidad: “la identidad narrativa no equivale a una ipseidad verdadera sino gracias a este momento decisivo, que hace de la responsabilidad ética el factor supremo de la ipseidad" (RICOEUR, 1996, Tomo III, p. 1001).

Estas ideas nos permiten proponer, en términos pedagógicos, que la finalidad de las prácticas autobiográficas en la educación, esto es, su contribución al logro de la condición de auténtico agente educativo, tanto en los profesores como en los alumnos, no consiste en elegir o descubrir la opción del relato que más unidad o consistencia propongan, sino en determinar el "espacio de inquietudes" del que parten y se proyectan los educadores y educandos. El "espacio de inquietudes" va a proporcionar más unidad al relato autobiográfico pero, sobre todo, más sentido al expresar el horizonte de búsquedas, las obligaciones que se asumen, las responsabilidades que se adquieren, la elaboración y aparición de "mi personaje». En relación con los docentes, esas inquietudes, el "jaqui estoy!", creo que se podría situar en el impulso vivificador de querer ser y actuar de otro modo, con otro estilo, para otros fines. Enmarco lo vivido en mi presente, en alguna de las vinculaciones posibles, pero me sitúo y sitúo mi profesión docente en la perspectiva de un compromiso personal, en el proyecto de ser, estar y proyectarme mejor como educador ante mis alumnos. El conocimiento de sí tiene de trasfondo el futuro, lo narrable como sentido autoafirmativo, de querer ser mejor educador.

\section{BIBLIOGRAFÍA}

AMOS HATCH, J. y WISNIEWSKI, R. (1995): Life history and narrative: questions, issues, and exemplary works. En Autores (eds.): Life history and narrative. Falmer Press, London, pp. 113-136.

ARENDT, H. (1993): La condición bumana. Paidós, Barcelona.

BÁRCENA, F. (1999): La memoria en educación y el cultivo de la humanidad. Por un nuevo pensar educativo. En PÉREZ-CAMINO, F. et al. Nacionalidad, bistoria y educación. Fundación Cives, Madrid (en prensa).

BOLÍVAR, A.; DOMINGO, J. y FERNÁNDEZ, M. (1998): La investigación biográfico-narrativa en educación. Guia para indagar en el campo. FORCE-Universidad de GranadaGrupo Editorial Universitario, Granada.

BRUNER, J. (1988): Realidad mental y mundos posibles. Los actos de imaginación que dan sentido a la experiencia. Gedisa, Barcelona.

- (1990): Actos de significado. Más allá de la revolución cognitiva. Alianza, Madrid.

CARR, David (1986): Time, narrative and bistory. Indiana University Press, Bloomington.

COSTE, D. (1989): Narrative as communication. University Minnesota Press, Minneapolis.

DERRIDA, J. (1994): Márgenes de la Filosofía. Cátedra, Madrid.

FENSTERMACHER, G.D. (1997): On narrative. Teaching and Teacher Education. Vol.13, n. 1, pp. 119-124. 
GERGEN, K.J. (1996): Realidades y relaciones: aproximaciones a la construcción social. Paidós, Barcelona.

GIL CANTERO, F. (1997): Educación y narrativa: la práctica de la autobiografía en la educación. Revista Inteuniversitaria de Teoría de la Educación. vol. 9, pp. 115-136.

GODZICH, W. (1989): Foreword: the time machine. En COSTE, D. Narrative as communication. University of Minnesota Press, Minneapolis, pp. 9-18.

GRASS, G. (1994): La dictadura de lo secundario. Suplemento literario de El País, Babelia, 13 de agosto, pp. 9-10.

GROPUE D'ENTREVERNES (1979): Analyse sémiotique des textes. Presses Universitaries de Lyon. Lyon.

GRUMET, M.R. (1981): Restitution and reconstruction of educacional experience: an autobiographical method for currículum theory. En LAWN, M. Y BARTON, L. (eds.): Retbinking curriculum studies. John Wiley, New York.

HARDY, B. (1975): Tellers and listeners: the narrative imagination. The Atthlone Press, London. HEISE, U.K. (1997): Chronoschisms. Time, narrative and postmodernism. Cambridge University Press, Cambridge.

JIMÉNEZ, J. (1989): La vida como azar. Mondadori, Madrid.

JOVER, G. y REYERO, D. (1999): Las imágenes del otro en la infancia. Fundación Crecer Jugando, Madrid.

KELCHTERMANS, G. (1993): Getting the story, understanding the lives: from career stories to teachers' professional development. Teaching and Teacher Education. Vol.9, n. 5-6, pp. 443-456.

LARROSA, J. (1996): La experiencia de la lectura. Estudios sobre literatura y formación. Laertes, Barcelona.

LLEDÓ, E. (1994): Memoria de la ética. Taurus, Madrid.

LÓPEZ BARAJAS, E. (coord.) (1996): Las bistorias de vida y la investigación biográfica. Fundamentos y metodología. UNED, Madrid.

MAcINTYRE, A. (1987): Tras la virtud. Crítica, Barcelona.

MAHABIR, H. (1997): Autobiography as a way of knowing. En CLANDININ, J. (ed.): Learning to teach, teaching to learn: stories of collaboration in teacher education. Teachers College Press, New York, pp. 19-27.

MARÍAS, Javier (1993): Autobiografía y ficción. En Autor, Literatura y fantasma. Siruela, Madrid, pp. 62-69.

- (1997): Basura sobre las estatuas. En Autor, Mano de sombra. Alfaguara, Madrid, pp. 21-23.

McEWAN, H. (1997): The functions of narrative and research on teaching. Teaching and Teacher Education. Vol. 13, n. 1, pp. 85-92.

MÈLICH, J.-C. (1998): Totalitarismo y fecundidad. La Filosofía frente a Auscbwitz. Anthropos, Barcelona.

MUÑOZ MOLINA, A. (1995): Entrevista a A. Muñoz Molina. Babelia, 18 de marzo, pp. 4-5.

ORTEGA y GASSET, J. (1973): Historia como sistema. En Autor, Obras Completas, vol.VI. Revista de Occidente, Madrid, $6^{a}$ ed., pp. 13-50.

REIS, C. y LOPES, A.C.M. (1995): Narratividad. En Autor: Diccionario de Narratologia. Ediciones Colegio de España. Salamanca, pp.166-172.

RICOEUR, P. (1987): Tiempo y narración. Tomo I: configuración del tiempo en el relato bistórico. Cristiandad, Madrid.

- (1996): Tiempo y narración. Tomo III: el tiempo narrado. Siglo XXI, Madrid.

- (1999): Historia y narratividad. Paidós-ICE de la Universidad de Barcelona, Barcelona.

(C) Ediciones Universidad de Salamanca

Teor. educ. 11,1999 , pp. 159-181 
RIVERA, J. A. (1998): Contingencia y narratividad. Claves de Razón Práctica. n. 83, pp. 2233 y n. 84 , pp. 37-45.

STIBBS, A. (1991): Reading narrative as literature: signs of life. Open University Press, London.

TAYLOR, Ch. (1994): La ética de la autenticidad. Paidós-I.C.E de la Universidad Autónoma de Barcelona, Barcelona.

- (1996): Fuentes del yo. La construcción de la identidad moderna. Paidós, Barcelona.

TODOROV, T. (1969): Grammaire du Décameron. The Hague, Mounton.

VALDECANTOIS, A. (1996): El sujeto construido. En CRUZ, M. (comp.): Tiempo de subjetividad. Paidós, Barcelona, pp. 194-220.

ZAMBRANO, M. (1989): Delirio y destino. Mondadori, Madrid. 